\title{
Interleukin-18 as a diagnostic marker of adult-onset Still's disease in older patients: a case report and review of the literature
}

\author{
Daisuke Usuda ${ }^{12^{*}}$, Yoshiki Furumura ${ }^{2}$, Kento Takeshima², Ryusho Sangen², Yasuhiro Kawai ${ }^{1}$, Yuji Kasamaki ${ }^{2}$,
} Yoshitsugu linuma ${ }^{1}$ and Tsugiyasu Kanda ${ }^{2}$

\begin{abstract}
Background: Adult onset Still's disease is a systemic auto-inflammatory condition of unknown etiology characterized by intermittent spiking high fever, an evanescent salmon-pink or erythematous maculopapular skin rash, arthralgia or arthritis, and leukocytosis. Recently, a high level of interleukin-18 has been reported as a new characteristic marker. On the other hand no reports have been published on high interleukin-18 as a marker in older patients. We report a case of adult onset Still's disease in an older patient successfully treated with steroids in which interleukin-18 was a useful marker of disease activity.

Case presentation: A 66-year-old Asian woman presented to our hospital with fever and arthralgia. We diagnosed adult onset Still's disease based on Yamaguchi criteria and a history of a high spiking fever, salmon-colored rash, and bilateral pain to shoulders, knees, and wrists. In this case, a high serum level of interleukin-18 was a diagnostic parameter. Administration of $40 \mathrm{mg}$ of prednisolone followed by subcutaneous administration of $200 \mathrm{mg}$ cyclosporine daily resulted in a dramatic resolution of our patient's febrile episodes 2 months after admission. Prednisolone was tapered to $5 \mathrm{mg} /$ day every 2 weeks and cyclosporine $200 \mathrm{mg} /$ day was continued. Her serum interleukin-18 level was prominently decreased, and she was discharged 3 months after treatment.

Conclusions: Serum interleukin-18 level may be a good diagnostic biomarker to monitor adult onset Still's disease activity in older patients, measuring levels in both the acute and convalescent phases.
\end{abstract}

Keywords: Interleukin-18, Adult-onset Still's disease, Diagnostic marker, Elderly patients, Older patients

\section{Background}

Adult onset Still's disease (AOSD) is a systemic auto-inflammatory condition of unknown etiology, characterized by intermittent spiking high fever, an evanescent salmon-pink or erythematous maculopapular skin rash, arthralgia or arthritis, and leukocytosis [1]. High serum ferritin levels, elevated erythrocyte sedimentation rate, high C-reactive protein levels, and an absence of antinuclear antibody (ANA) and rheumatoid factor are common laboratory findings [2]. A high level of interleukin (IL)-18 has recently been reported as a new

\footnotetext{
* Correspondence: united19771108@yahoo.co.jp

1Department of Infectious Diseases, Kanazawa Medical University, 1-1 Daigaku, Uchinada-machi, Ishikawa-ken, Japan

2Department of Community Medicine, Kanazawa Medical University Himi Municipal Hospital, 1130 Kurakawa, Himi-shi, Toyama-ken, Japan
}

characteristic marker; however, no such report focusing on older patients has been published $[3,4]$.

\section{Case presentation}

A 66-year-old Asian woman presented to our hospital with a 2-week history of continuous high quotidian fever, pain to her right elbow and bilateral lower limbs, and erythematous rash. She was admitted for examination and treatment. Her temperature on admission was $39{ }^{\circ} \mathrm{C}$, and it ranged from 39 to $40{ }^{\circ} \mathrm{C}$ daily. Her past medical history was negative except for celecoxib allergy. She was married; however, her bedridden husband was under care at a nursing facility due to cerebrovascular disease, and her two adult daughters lived separately. She had been engaged in cleaning work and farming until 1 month prior to her visit to our hospital. A

(c) The Author(s). 2018 Open Access This article is distributed under the terms of the Creative Commons Attribution 4.0 International License (http://creativecommons.org/licenses/by/4.0/), which permits unrestricted use, distribution, and 


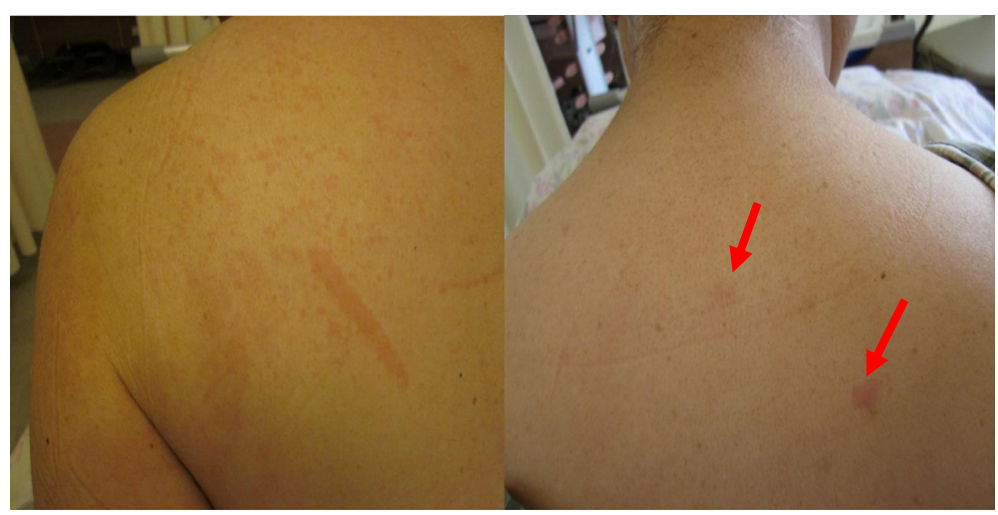

Fig. 1 A salmon-pink papular eruption was evident on the upper back (red arrows)

detailed dermatological examination revealed a confluent salmon-pink papular eruption to her upper back area (Fig. 1). Further physical examination revealed mild splenomegaly and a tender right wrist. A laboratory profile revealed elevated serum ferritin levels (9692 mg/mL) but no leukocytosis. Her serum IL-18 level was markedly elevated (140,373 pg/mL); her rheumatoid factor was positive (22 IU/ $\mathrm{mL})$. Autoantibodies such as ANA, anti-neutrophil cytoplasmic antibody, matrix metalloproteinase-3, serologic test for hepatitis $B$ and $C$, urine analysis, and $2 / 2$ sets of blood culture were negative. Chest-abdomen computed tomography showed splenomegaly. Gallium scintigraphy showed accumulation to bilateral knees, shoulders, and wrists (Fig. 2).

Clinical and laboratory findings on admission were consistent with a diagnosis of AOSD based on Yamaguchi criteria [1]. Oral administration of $35 \mathrm{mg} /$ day $(0.5 \mathrm{mg} / \mathrm{kg}$ per day) prednisolone was started on day 9 of hospitalization; however, fever and arthralgia persisted. Therefore, prednisolone

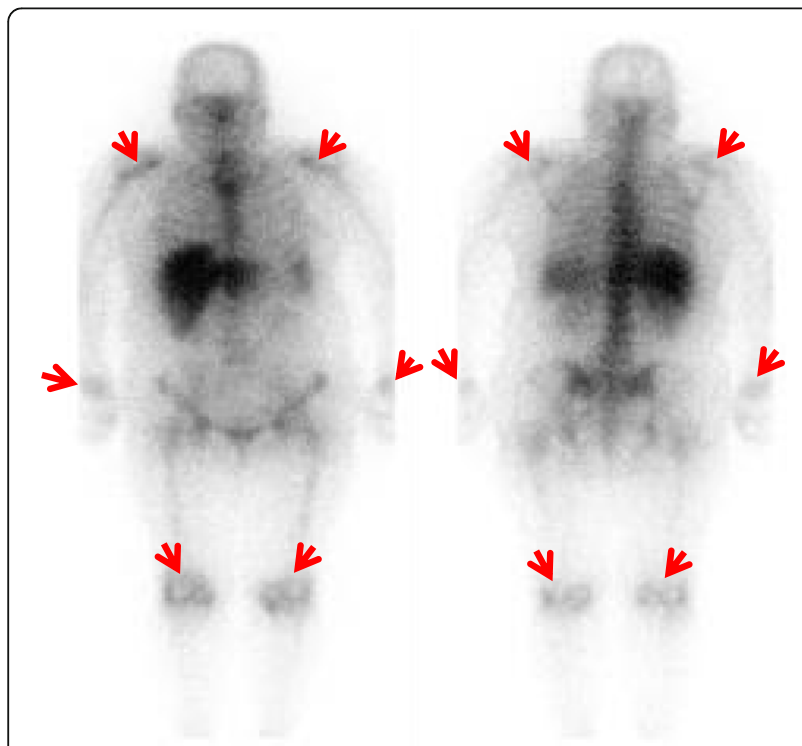

Fig. 2 Gallium scintigraphy showed accumulation (red arrows) was increased to $40 \mathrm{mg} /$ day and cyclosporine $200 \mathrm{mg} /$ day administered orally was added on day 20 of hospitalization, which resulted in a dramatic resolution of our patient's febrile episodes and polyarthralgia. Prednisolone was tapered $5 \mathrm{mg} /$ day every 2 weeks and cyclosporine $200 \mathrm{mg} /$ day was continued. Serum levels of ferritin and IL-18 on day 99 of illness were markedly decreased to $212 \mathrm{mg} / \mathrm{dL}$ and $1078 \mathrm{pg} / \mathrm{mL}$, respectively. She was discharged on day 111 of hospitalization (Fig. 3). Cyclosporine was continued at the same dosage and prednisolone was gradually tapered. Regular follow-up examinations showed no relapse of symptoms. On day 305 of illness, her serum levels of ferritin and IL-18 were decreased to $14 \mathrm{mg} / \mathrm{dL}$ and $190 \mathrm{pg} / \mathrm{mL}$, respectively (Fig. 4).

\section{Discussion and conclusions}

The criteria for AOSD diagnosis proposed by Yamaguchi include high spiking fever and salmon-like evanescent rash. In addition, joint involvement and myriad nonspecific symptoms may occur [2]. AOSD diagnosis remains one of exclusion, ruling out infectious, autoimmune, or malignant conditions, and is defined by Yamaguchi classification criteria. The pivotal role of the macrophage is cell activation and release of Th1-type inflammatory cytokines [5]. It remains difficult, however, to determine predictive factors of outcome and to draw guidelines for patient management.

AOSD is rare and exhibits a bimodal age distribution with one peak incidence between ages of 15 and 25 and a second peak between ages of 36 and 46 years [6]. The frequency of AOSD in older people is unknown [7]. The immune system in older patients undergoes a functional remodeling. After menopause, the incidence of chronic inflammatory disease in women approaches or exceeds that observed in men. The immune system of aged individuals is quite different from that of a young or middle-aged adult, and these differences correlate with increased susceptibility to various infections, the reduced efficacy of some vaccinations, and a greater risk of 


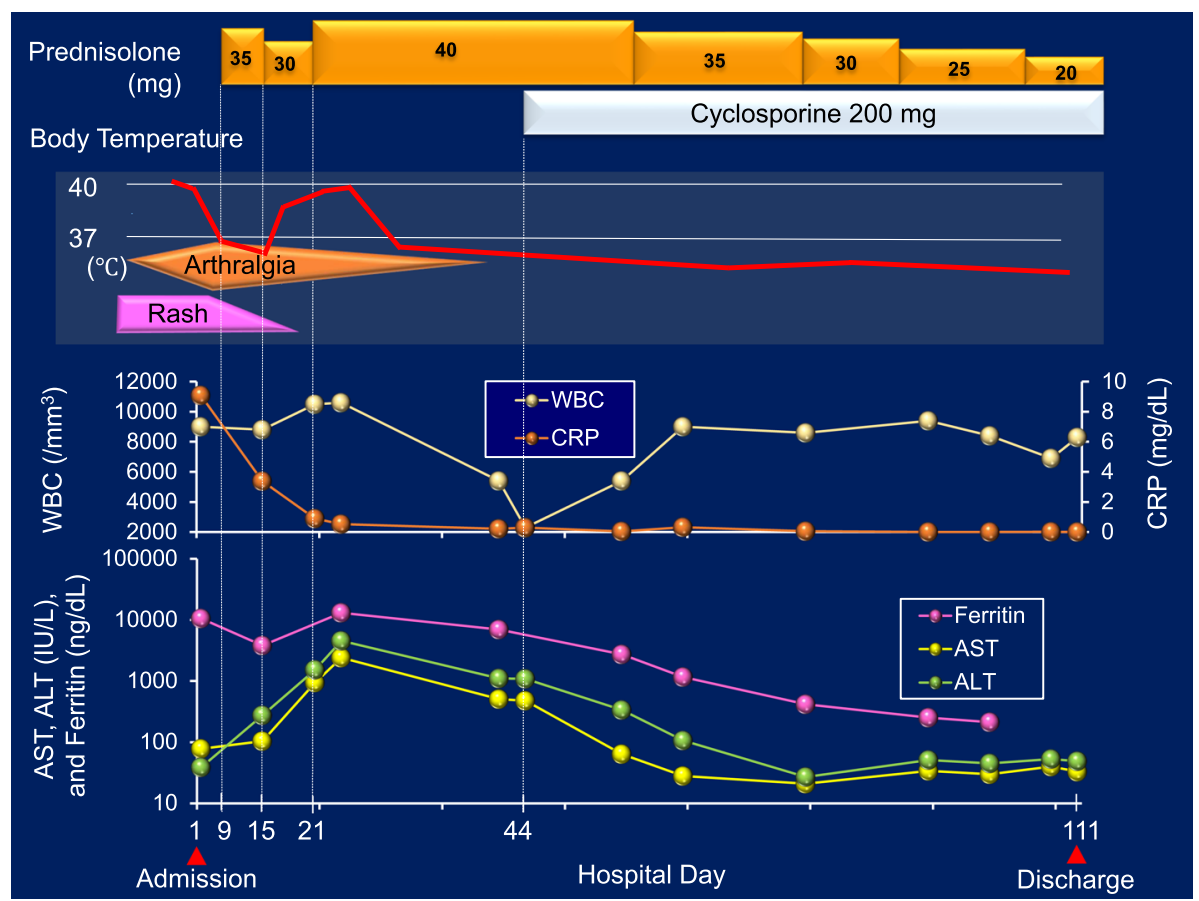

Fig. 3 Clinical course of the patient. ALT alanine aminotransferase, AST aspartate aminotransferase, CRP C-reactive protein, WBC white blood cells

chronic disease driven by chronic inflammation [8]. In this case our patient was greater than 65 years of age and was, therefore, likely to have some degree of immunological impairment, which could have induced AOSD. The number of older patients with AOSD is likely to increase in the future because this age group is susceptible to immunological dysfunction; therefore, awareness of this disease should be increased.

IL-18 was first described in 1999 [9]. The main source of IL-18 in humans is mononuclear cells, such as monocytes, macrophages, dendritic cells, and lymphocytes B
[10]. Macrophage activation is a hallmark of AOSD, and serum from patients with AOSD discloses a dramatic increase in growth and differentiating factors for macrophages [10]. This cytokine plays effector and regulatory roles in a variety of early inflammatory responses. It is also expressed at sites of chronic inflammation, in autoimmune disease, a variety of cancers, and the context of numerous infectious diseases [11]. The dramatic effects of cytokine storms are now well documented in AOSD. The serum level of IL-18 was reported to be correlated with disease activity and ferritin serum level [6]. IL-18

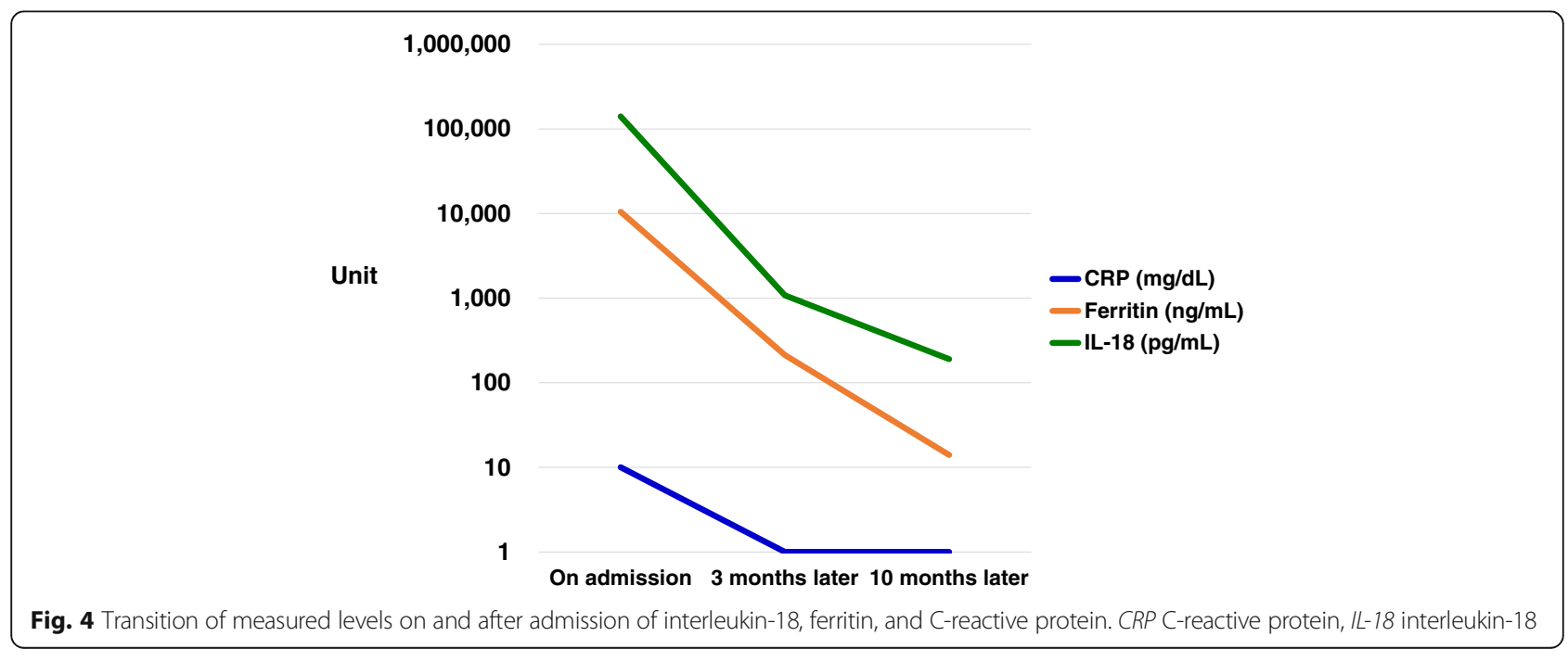


could play a central role in AOSD, and systemic expression may be responsible for tissue damage in target organs such as liver, spleen, and synovial membrane [12]. This suggests an important role in resistance to intracellular pathogens that can develop inside immune cells, including macrophages [13]. Our previous report demonstrated that IL-18 reduced viral infection due to enhancement of interferon-gamma and natural killer cell activity in an animal model [14].

Higher serum IL-18 levels were related to AOSD disease activity, and a positive significant correlation was confirmed between IL-18 serum levels and disease activity [4]. Furthermore, these levels were higher than those in rheumatoid arthritis, Sjögren's syndrome, and systemic lupus erythematosus, whose IL-18 levels were lower than $3000 \mathrm{pg} / \mathrm{mL}$ [4]. In a previous article, serum concentration of IL-18 was suggested as a diagnostic marker of AOSD; and in patients with active AOSD, it was higher than the highest value in healthy individuals and its cutoff point was $312.5 \mathrm{pg} / \mathrm{mL}$ for detection of AOSD [4]. In this case, it was greater than $100,000 \mathrm{pg} / \mathrm{mL}$ at admission.

We report the first case of AOSD in an older patient with rash typically associated with Still's disease in which serum IL-18 level was a good biomarker of AOSD activity in both acute and convalescent phase. Serum IL-18 level could be a diagnostic marker in AOSD in older patients.

\section{Abbreviations}

ANA: Antinuclear antibody; AOSD: Adult-onset Still's disease; IL: Interleukin

Availability of data and materials

All data generated or analyzed during this study are included in this published article.

\section{Authors' contributions}

YF is the physician who handled the case; DU is a major contributor to the writing of the manuscript. All authors read and approved the final manuscript.

\section{Ethics approval and consent to participate}

This case report was approved by the Kanazawa Medical University Himi Municipal Hospital ethics committee, and carried out in conformance with the principles of the Declaration of Helsinki. Both verbal and written informed consent were obtained from the patient before submission.

\section{Consent for publication}

Written informed consent was obtained from the patient for publication of this case report and any accompanying images. A copy of the written consent is available for review by the Editor-in-Chief of this journal.

\section{Competing interests}

The authors declare that they have no competing interests.

\section{Publisher's Note}

Springer Nature remains neutral with regard to jurisdictional claims in published maps and institutional affiliations.
Received: 5 September 2017 Accepted: 1 June 2018

Published online: 10 July 2018

\section{References}

1. Yamaguchi M, Ohta A, Tsunematsu T, Kasukawa R, Mizushima Y, Kashiwagi H, Kashiwazaki S, Tanimoto K, Matsumoto Y, Ota T, et al. Preliminary criteria for classification of adult Still's disease. J Rheumatol. 1992;19(3):424-30.

2. Fautrel B. Adult-onset still disease. Best Pract Res Clin Rheumatol. 2008;22(5): 773-92. https://doi.org/10.1016/j.berh.2008.08.006.

3. Jung KH, Kim JJ, Lee JS, Park W, Kim TH, Jun JB, Yoo DH. Interleukin-18 as an efficient marker for remission and follow-up in patients with inactive adult-onset Still's disease. Scand J Rheumatol. 2014;43(2):162-9. https://doi. org/10.3109/03009742.2013.824023. Epub 2013 Oct 18

4. Colafrancesco S, Priori R, Alessandri C, Perricone C, Pendolino M, Picarelli G, Valesini G. IL-18 serum level in adult onset Still's disease: a marker of disease activity. Int J Inflam. 2012;2012:156890. https://doi.org/10.1155/2012/156890. Epub 2012 Jun 18

5. Chen DY, Lan JL, Lin FJ, Hsieh TY. Proinflammatory cytokine profiles in sera and pathological tissues of patients with active untreated adult onset Still's disease. J Rheumatol. 2004;31(11):2189-98.

6. Priori R, Colafrancesco S, Alessandri C, Minniti A, Perricone C, laiani G, Palazzo D, Valesini G. Interleukin 18: a biomarker for differential diagnosis between adult-onset Still's disease and sepsis. J Rheumatol. 2014;41(6): 1118-23. https://doi.org/10.3899/jrheum.130575. Epub 2014 May 1

7. Limsukon A, Jones HD, Feinstein J. A 60-year-old Japanese man with fevers, myalgias, pharyngitis, and right knee pain. Chest. 2009;136(5):1428-31. https://doi.org/10.1378/chest.09-0722.

8. Gubbels Bupp MR. Sex, the aging immune system, and chronic disease. Cell Immunol. 2015;294(2):102-10. https://doi.org/10.1016/j.cellimm.2015.02.002. Epub 2015 Feb 10

9. $\quad$ lliou C, Papagoras C, Tsifetaki N, Voulgari PV, Drosos AA. Adult-onset Still's disease: clinical, serological and therapeutic considerations. Clin Exp Rheumatol. 2013;31(1):47-52. Epub 2012 Sep 25

10. Janiak A, Leśniowski B, Jasińska A, Pietruczuk M, Małecka-Panas E. Interleukin 18 as an early marker or prognostic factor in acute pancreatitis. Prz Gastroenterol. 2015;10(4):203-7. https://doi.org/10.5114/pg.2015.50993. Epub 2015 Apr 20

11. Fabbi M, Carbotti G, Ferrini S. Context-dependent role of IL-18 in cancer biology and counter-regulation by IL-18BP. J Leukoc Biol. 2015;97(4):665-75. https://doi.org/10.1189/jlb.5RU0714-360RR. Epub 2014 Dec 29

12. Maria AT, Le Quellec A, Jorgensen C, Touitou I, Rivière S, Guilpain P. Adult onset Still's disease (AOSD) in the era of biologic therapies: dichotomous view for cytokine and clinical expressions. Autoimmun Rev. 2014;13(11): 1149-59. https://doi.org/10.1016/j.autrev.2014.08.032. Epub 2014 Aug 27

13. Wawrocki S, Druszczynska M, Kowalewicz-Kulbat M, Rudnicka W. Interleukin 18 (IL-18) as a target for immune intervention. Acta Biochim Pol. 2016;63(1): 59-63. https://doi.org/10.18388/abp.2015 1153. Epub 2016 Feb 17

14. Kanda T, Tanaka T, Sekiguchi K, Seta Y, Kurimoto M, Wilson McManus JE, Nagai R, Yang D, McManus BM, Kobayashi I. Effect of interleukin-18 on viral myocarditis: enhancement of interferon- gamma and natural killer cell activity. J Mol Cell Cardiol. 2000;32(12):2163-71.
- fast, convenient online submission

- thorough peer review by experienced researchers in your field

- rapid publication on acceptance

- support for research data, including large and complex data types

- gold Open Access which fosters wider collaboration and increased citations

- maximum visibility for your research: over $100 \mathrm{M}$ website views per year

At BMC, research is always in progress.

Learn more biomedcentral.com/submissions 